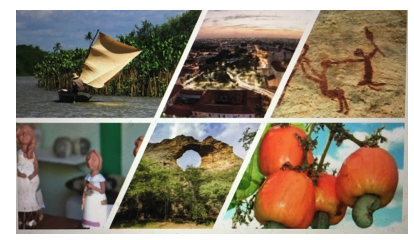

\title{
VIDA, EDUCAÇÃO E PROFISSÃO: PERCURSOS DE (TRANS)FORMAÇÃO NA TRAJETÓRIA DE NESTOR DOS SANTOS LIMA
}

\author{
Sara Raphaela Amorim \\ Doutora em Educação pela Universidade do Estado do Rio de Janeiro \\ Professora Adjunta na Universidade do Estado do Rio Grande do Norte \\ Lattes Id: http://lattes.cnpq.br/4398674052996842
}

\begin{abstract}
RESUMO
Investigar os percursos de (trans)formação na trajetória do educador norte-rio-grandense Nestor dos Santos Lima é o objetivo desta pesquisa. Com vasta atuação na educação pública do Rio Grande do Norte, Nestor Lima foi responsável por cargos como a direção da Escola Normal de Natal (1911-1923) e do Departamento de Educação (1924-1928). Nestes espaços escreveu diversos tipos de documentos oficiais, a exemplo dos relatórios de funcionamento da Escola Normal de Natal, relatório do Departamento de Educação do Estado (1924-1928) e dois relatórios de viagens pedagógicas comissionadas nos anos de 1913 e 1923. Diante de tantos registros administrativos, surge a questão: como perceber subjetividades da vida de um educador na escrita de documentos oficiais? Para responder a esta questão faço uso da pesquisa documental, reconhecendo as especificidades do trabalho com fontes históricas abordadas por Nunes e Carvalho (1993), Bacellar (2010) e Vasconcelos (2014), em diálogo com Mignot (2002) e Souza (2015), que versam sobre os desafios e possibilidades da pesquisa (Auto)Biográfica. Castillo Gómez (2004) fundamenta as discussões sobre da História da Cultura Escrita, assim como Chartier (1994; 2002; 2003) contribui para o trabalho com os aspectos da materialidade dos suportes. A problematização e análise das fontes permitiram capturar singularidades da trajetória de formação, interesses e relações políticas de Nestor Lima, a partir da compreensão do movimento dialético de construção de suas identidades pessoal e profissional no cotidiano. Nos rastros dos documentos oficiais que assinou, faço incursões de um olhar curioso, sigo vestígios, conjecturo e construo sentidos possíveis.
\end{abstract}

Palavras-chave: Escrita. Fontes Documentais. Trajetória Profissional. Vida e educação.

\section{LIFE, EDUCATION AND PROFESSION: COURSES OF (TRANS)FORMATION IN THE TRAJECTORY OF NESTOR DOS SANTOS LIMA}




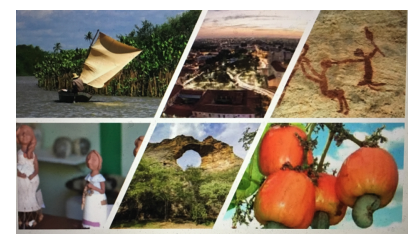

\begin{abstract}
This research aims to investigate the courses of (trans)formation in the trajectory of the norte-rio-grandense educator Nestor dos Santos Lima. With extensive experience in public education in Rio Grande do Norte, Nestor Lima held positions such as the direction of the Natal Normal School (1911-1923) and the Department of Education (1924-1928). In these periods he wrote several types of official documents, such as the operating reports of the Natal Normal School, the State Department of Education report (1924-1928) and two reports of commissioned pedagogical trips in 1913 and 1923. With so many administrative records, a question arises: how to see the subjectivities of an educator's life in the writing of official documents? To answer this question I use a documentary research, recognizing the specificities of work with historical sources approached by Nunes and Carvalho (1993), Bacellar (2010) and Vasconcelos (2014), in dialogue with Mignot (2002) and Souza (2015), which deal with the challenges and possibilities of (Auto)Biographical research. Castillo Gómez (2004) grounds the discussions on the History of Written Culture, as Chartier $(1994 ; 2002 ; 2003)$ contributes to the work with the aspects of the materiality of supports. The problematization and analysis of the sources allowed us to capture singularities of Nestor Lima's trajectory of formation, interests and political relations, from the understanding of the dialectical movement of building his personal and professional identities in daily life. In the trails of the official documents he has signed, I make incursions of a curious look, follow traces, conjecture, and then I create possible meanings.
\end{abstract}

Key-words: Writing. Documentary Sources. Professional Trajectory. Life and Education.

\title{
VIDA, EDUCACIÓN Y PROFESIÓN: RECORRIDOS DE LA (TRANS)FORMACIÓN EN LA TRAYECTORIA DE NESTOR DOS SANTOS LIMA
}

\section{RESUMEN}

Investigar los recorridos de la (trans)formación en la trayectoria del educador norte riograndense Nestor dos Santos Lima es el objetivo de esta investigación. Con amplia actuación en la educación pública de Rio Grande do Norte, Nestor Lima fue el responsable por cargos como la dirección de la Escuela Normal de Natal (1911-1923) y del Departamento de Educación (1924-1928). En estos espacios escribió diversos tipos de documentos oficiales, como ejemplo de los informes de funcionamiento de la Escuela Normal de Natal, informe del Departamento de Educación del Estado (1924-1928) y dos informes de viajes pedagógicos comisionados en los años de 1913 y 1923 . Frente a tantos registros administrativos, surge la cuestión: ¿cómo percibir las subjetividades de la vida 


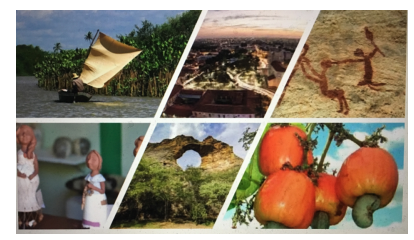

de un educador en la escritura de documentos oficiales? Para responder a esta cuestión uso la investigación documental, reconociendo las especificidades del trabajo con fuentes históricas abordadas por Nunes y Carvalho (1993), Bacellar (2010) y Vasconcelos (2014), en diálogo con Mignot (2002) y Souza (2015), que abordan los desafíos y posibilidades de la investigación (auto)biográfica. Castillo Gómez (2004) fundamenta los debates sobre la Historia de la Cultura Escrita, como Chartier (1994; 2002; 2003) contribuye para el trabajo con los aspectos de la materialidad de los suportes. La problematización y análisis de las fuentes permitieron capturar las singularidades de la trayectoria de formación, intereses y relaciones políticas de Nestor Lima, a partir de la comprensión del movimiento dialéctico de la construcción de sus identidades personal y profesional en el cotidiano. En los rastros de los documentos oficiales que firmó, hago incursiones de una mirada curiosa, sigo vestigios, conjeturo y construyo sentidos posibles.

Palabras-clave: Escritura. Fuentes Documentales. Trayectoria Profesional. Vida y educación.

Pensar questões educacionais a partir da perspectiva histórica exige do pesquisador atenção e sensibilidade para enxergar e considerar os mais diversos elementos que compreendem seu universo de construção, desde aspectos políticos e materiais de organização, às atuações daqueles e daquelas que direta ou indiretamente idealizaram, propuseram, reivindicaram e/ou contribuíram para os direcionamentos que orientaram historicamente o desenvolvimento da educação no nosso país.

A pesquisa em História da Educação tem dialogado de forma cada vez mais próxima com a pesquisa Autobiográfica e as histórias de vida, possibilitado a ampliação de questões teórico-metodológicas, sobretudo no tocante a diversidade de objetos, fontes e perspectivas de investigações. De acordo com Sousa e Menezes (2006, p.146) “o âmbito da História da Educação e de outros campos do conhecimento educacional, as pesquisas com fontes menos tradicionais e mais recorrentes começam a ter e adquirir novo estatuto metodológico e apresentam novos esforços para uma compreensão das práticas educativas e escolares".

Além do conhecimento das práticas educativas e escolares desenvolvidas nos mais distintos momentos históricos da educação nacional, as trajetórias dos educadores têm adquirido relevo, visto que iniciativas e projetos educacionais surgem a partir das Revista Caminhos da Educação: diálogos, culturas e diversidades. CAEDU/UFPI 56 Teresina, Brasil, v. 1, n. 1, p. 54-79, janeiro/abril de 2019

DOI: 


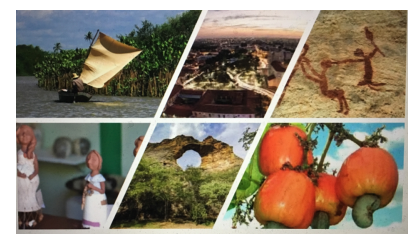

reflexões de sujeitos e/ou grupos que motivados por suas intenções políticas, no sentido mais amplo do termo, investiram tempo e somaram esforços para a formulação de propostas educacionais que contribuíssem para o que almejava cada sociedade em seu respectivo contexto sóciohistórico, político e econômico.

Destaco, portanto, não apenas os usos e intepretações de fontes menos tradicionais, como também o trabalho com documentos oficiais da educação, porém, a partir de leituras que abrem espaço para as incursões do pesquisador. Partindo do entendimento de que as ações educativas não são neutras de intenções, compreendo que para investigar trajetórias de profissionais da educação, torna-se imprescindível voltar o olhar para a vida dessas pessoas, dentre aspectos que versem acerca de formação, percursos, espaços de atuação e redes estabelecidas em um diálogo íntimo entre docência e vida.

\section{“TRABALHAR COM VIDAS É DAR VIDA ÀS HISTÓRIAS"}

Os limites entre a trajetória de construção da vida pessoal e profissional por vezes podem parecer tênues, o que significa que investigar os caminhos de formação de um educador suscita, por parte do pesquisador, a construção de novos percursos que possibilitem uma aproximação com vida e obra daquele que deseja conhecer, lançandose assim em uma jornada, mediada pelas fontes, indícios e vestígios nos espaços de construção da identidade profissional e/ou pessoal do indivíduo pesquisado.

De acordo com Mignot (2002, p.20) “identidade pessoal e profissional se constrói cotidianamente" e, fazendo referência à Clarice Nunes, a autora aponta para a importância de recuperar o percurso de formação para que a especificidade da trajetória não se dilua nas análises homogeneizadas de determinado momento histórico e suas questões políticas educacionais. Considero relevante a realização de um movimento dialético de

\footnotetext{
${ }^{1}$ Referência à frase de autoria de Ana Chrystina Mignot no livro Baú de Memórias, bastidores de histórias: o legado pioneiro de Armanda Álvaro Alberto (2002).
} 


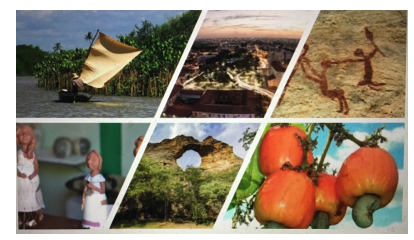

compreensão do sujeito em meio ao seu contexto histórico de vida e atuação com o devido cuidado de não perder as especificidades de trajetória de seu percurso formativo, em meio à homogeneização de um ideário educacional, porém, com a atenção para também perceber a vida, sem negligenciar as questões relativas às instituições e/ou movimentos educativos que ele integrou, considerando que suas singularidades compõem os processos escolhas e atuação docente.

Cercada desses cuidados, me aventuro na escrita deste texto, discutindo a trajetória do educador norte-rio-grandense de Nestor dos Santos Lima, a partir do olhar lançado sobre as fontes documentais que trazem em si indícios dos caminhos por ele percorridos, as discussões das quais se ocupava em sua atuação na educação do estado e as construções de suas representações por meio da escrita para a qual estes materiais ofereceram suporte.

No final do século XIX, mais precisamente no dia 01 de agosto de 1887 em Assú, município do interior do Rio Grande do Norte, nasceu Nestor dos Santos Lima. Os estudos das primeiras letras aconteceram no seio de sua família, sob os cuidados de sua mãe, Ana Souto Lima e, desde a infância, Nestor Lima circulou em espaços sociais como as redações dos jornais locais de sua cidade natal. No Atheneu Norte-Rio-Grandense, com treze anos de idade, deu início aos estudos do curso secundário, concluído posteriormente no Liceu Paraibano em 1904. No ano seguinte, matriculou-se na Faculdade de Direito do Recife, pela qual foi titulado em 1909 como Bacharel em Ciências Jurídicas e Sociais.

A trajetória de formação de Nestor Lima aponta para suas possibilidades de circulação e atuação na sociedade norte-rio-grandense, bem como a constituição de redes de sociabilidade que legitimavam no trânsito em determinados espaços sociais. $\mathrm{O}$ acesso aos cursos superiores era restrito aos jovens das camadas mais abastadas da sociedade e ao examinar a Lista Geral dos Bacharéis da Faculdade de Direito do Recife (1828-1931), me deparo com nomes de destaque nacional, a exemplo de Luiz da Câmara Cascudo $^{2}$ e

\footnotetext{
2 Escritor e folclorista natural de Natal/Rio Grande do Norte (1898-1986). É um dos mais importantes pesquisadores das raízes étnicas do Brasil. Consultar: MAMEDE, Zila. Luís da Câmara Cascudo: 50 anos de vida intelectual, 1918-1968: bibliografia anotada. Natal: Fundação José Augusto, 1970. v.1, pt. 1. 


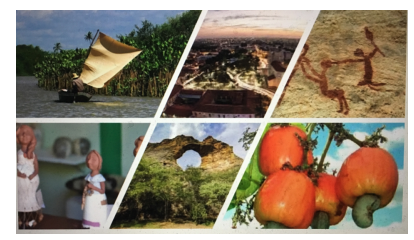

Antônio Carneiro Leão ${ }^{3}$. Muitos dos jovens formados pelas Faculdades de Direito em Recife e Medicina, em Salvador, estiveram no centro das discussões acerca da educação.

Com a formação de advogado, Nestor Lima prestou concurso para ingresso na Escola Normal de Natal, assumindo em 1909 a cadeira de Pedagogia. Dois anos depois, foi nomeado pelo então governador do estado Alberto Maranhão, para assumir a direção desta instituição de formação de professores, em 14 de março de 1911, permanecendo no cargo até o ano de 1923. No ano seguinte, em 1924, ele criou e tornou-se diretor do Departamento de Educação do Estado, órgão que substituiu a antiga Diretoria Geral da Instrução Pública e que almejava estabelecer novos rumos para a organização da educação no Rio Grande do Norte. Enquanto responsável por este cargo escreveu uma relevante massa documental composta por relatórios e regimentos de instituições oficiais de ensino a exemplo da Escola Normal de Natal, Grupos Escolares, Escolas Isoladas, Escolas Rudimentares, Departamento e Conselho de Educação.

A atuação profissional de Nestor Lima ocorre no contexto situado nas décadas iniciais do século XX, marcadas pelas Reformas Educacionais realizadas nos diversos estados brasileiros. A escola surgia como símbolo do progresso anunciado pela República, "nacionalizando as populações operárias rebeldes", como elucida Carvalho (2003, p.227). No Rio Grande do Norte, a reconfiguração do cenário educacional dá-se pela lei pela Lei no 249 , de 22 de novembro de 1907 e autorizada pelo decreto $\mathrm{n}^{\circ} 178$ de 29 de abril de 1908, popularmente conhecida como Reforma Pinto de Abreu. Sobre esse movimento, Mignot (2002, p. 31-32) assinala que "enquanto na Europa e nos EUA o movimento renovador surgia de iniciativas particulares, no Brasil eram de caráter público", visto que junto às mudanças na educação realizava-se a ação política de

\footnotetext{
${ }^{3}$ Advogado, educador e ensaísta, Carneiro Leão nasceu em Recife/PE, em 02 de julho de 1887 e faleceu no Rio de Janeiro/RJ, em 31 de outubro de 1966. Autor da Reforma da Educação no Estado de Pernambuco em 1928, atuou também Secretário de Estado do Interior, Justiça e Educação do Estado de Pernambuco (1929-1930) e diretor do Instituto de Pesquisas Educacionais da Prefeitura do Distrito Federal na administração Anísio Teixeira (1934). Criou e dirigiu o Centro Brasileiro de Pesquisas Pedagógicas da Universidade do Brasil. Em 1994, tornou-se membro da Academia Brasileira de Letras, sendo o segundo ocupante da cadeira 14.
}

Revista Caminhos da Educação: diálogos, culturas e diversidades. CAEDU/UFPI 


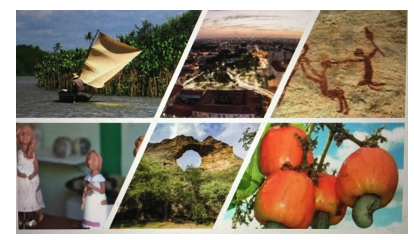

construção de uma identidade nacional nos anos iniciais da república, por meio da educação.

Longe da tentativa de conferir linearidade e ordem aos acontecimentos de uma vida, me arrisco a investigar e compreender a formação profissional de Nestor Lima em relação com os acontecimentos da proposta de reorganização da educação. Percebo em que em sua trajetória certas mudanças ocorreram a partir de seus percursos de formação profissional; novas aspirações a cada novo passo dado na profissão docente. Curiosamente, este é um momento de transformação na educação do Rio Grande do Norte, repleto de iniciativas políticas com foco na instrução e reorganização do ensino público. Neste movimento, percebo a abertura não apenas de novas instituições, mas, a possibilidade de outros espaços de atuação e discussão das pautas educacionais, onde Nestor Lima progressivamente se inseriu, em consonância com as concepções políticas dos grupos que se encontravam no poder.

Observo, em específico, dois momentos que considero singulares na (trans)formação profissional de Nestor dos Santos Lima. O primeiro, na direção da Escola Normal de Natal (1911-1923), responsável pela gestão institucional e escrita dos relatórios de funcionamento e o segundo, na direção do Departamento de Educação (1924-1928) onde reorganizou toda a estrutura da educação pública no estado. A partir das ocupações destes espaços, Nestor Lima foi também transformado. A produção escrita derivada das atribuições de gestão revela traços particulares de seu autor. É, também, neste momento histórico que o educador realiza duas viagens comissionadas com o intuito de observar a educação em outras localidades. "O sujeito que vai, definitivamente não é o que retorna. Em sua bagagem, os presentes recebidos, as experiências vividas e as possibilidades de novos caminhos; neste caso, caminhos com vistas à modernização do ensino no estado" (AMORIM, 2017, p.127).

Nestor Lima circulou em diversos espaços sociais, a exemplo da Associação de Professores do Rio Grande do Norte/APRN onde desde a fundação no ano de 1921 esteve presente e compartilhando suas ideias na Revista Pedagogium, periódico organizado pela 


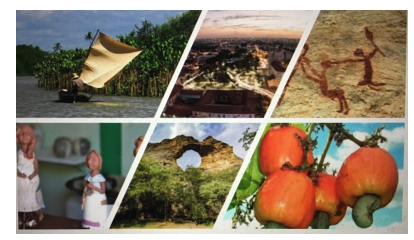

referida Associação. No Instituto Histórico e Geográfico do Rio Grande do Norte/IHGRN, foi admitido inicialmente como sócio efetivo em fevereiro de 1910, sendo também orador, secretário da Revista do Instituto Histórico e Geográfico do Rio Grande do Norte em várias administrações e por fim, eleito presidente em 17 de março de 1927, cargo que exerceu durante 32 anos, sendo considerado presidente perpétuo da Instituição. Para esta casa da memória, por meio de seu testamento, doou toda sua biblioteca, não apenas os volumes que a compunham, mas, inclusive, o mobiliário que os guardava.

A escrita de relatórios oficiais oportunizou a Nestor Lima um mecanismo de representação não apenas das questões educacionais vigentes, mas também de si. Em meio à leitura de proposições e necessidades da situação educacional do período, conheço também um pouco mais sobre o autor. Sua identidade se revela de muitos modos, seja pela escolha de tema, pela leitura feita de determinada localidade ou situação, ou até mesmo quando fala de si em meio às experiências vividas em cada espaço visitado/ocupado.

Esta investigação situa-se no entrecruzamento dos campos da História da Educação e da História da Cultura Escrita, assumindo escrita e leitura como objetos e práticas sociais produzidos em diferentes espaços e temporalidades. Castillo Gómez (2004, p.91) ressalta a necessidade de considerar as " [...] formas, funciones y usos de lo escrito, en los mecanismos y lugares de adquisición, en las redes de sociabilidad de escribientes y analfabetos, en las políticas de la escritura y del escribir, en los modos de circulación y a apropiación, o en las maneras, tipologías y espacios de la lectura”.

Ao trabalhar com documentos oficiais é necessário ter clareza de que eles são, como todas as demais fontes históricas, registros de versões de um passado e não se constituem, portanto, enquanto detentores de toda pluralidade de uma época, são pistas e formas de ver o mundo, como nos alerta Mignot (2002). Os sentidos não se constroem sozinhos, sem as necessárias perguntas daqueles que os leem. Por isso a pesquisa, atividade nuclear da ciência, necessita de averiguação minuciosa, com o auxílio de 


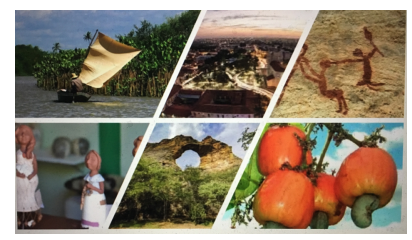

procedimentos específicos e referencias que auxiliem na compreensão da historicidade dos documentos.

Vasconcelos (2014, p. 40-41) apresenta importantes reflexões acerca da pesquisa em documentos oficiais e possibilidades de interpretação:

A pesquisa em documentos oficiais como relatórios escritos por dirigentes ou autoridades sobre o seu próprio trabalho, também se constitui em uma fonte importante, uma vez que contém as informações governamentais do período enfocado. Normalmente, esses documentos têm como característica, embora por vezes manipulada, o levantamento de dados relativos à situação da instrução pública, fragmentos da memória instituída, com ênfase nas condições de oferta e demanda no período estudado. Ao realizar uma investigação histórica que objetiva fazer uma recomposição do passado por meio de uma pesquisa essencialmente bibliográfica e documental, torna-se necessário entender a importância dos registros oficiais como testemunhos para a construção da memória, ou seja, quem escrevia, para quem e com que finalidade.

Na busca pelo que é passível de ser percebido nas entrelinhas, sigo vestígios, conjecturo, construo sentidos possíveis. Na ausência de um arquivo privado, procurei reinventar Nestor a partir dos seus rastros nos documentos oficiais que assinou, incursões de um olhar curioso. Fiz uso das fontes como passaportes para adentrar em seus espaços de atuação, que se configuram como elementos fundamentais para a compressão das transformações vividas no meio percurso, laços estabelecidos, investigando a reciprocidade das mudanças na vida pessoal e profissional.

Castillo Gomez (2003, p.94) escreveu que "la escritura puede ser todo aquello que nosotros seamos capaces de leer en ella.. " corroboro com esta ideia pela compreensão de que na tecitura deste texto não me proponho a descrever, mas assumo a escrita de uma versão da trajetória profissional de Nestor Lima, representada a partir dos recortes que

\footnotetext{
${ }^{4} \mathrm{O}$ autor faz referência a Faz referência a Giorgio R. Cardona em "Storia universale della scrittura", Milano, Mondadori, 1986.
} 


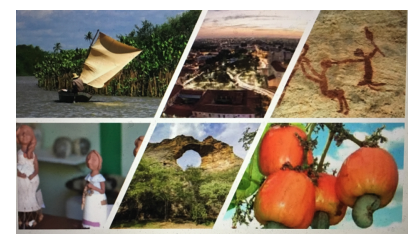

estabeleço no trabalho com as fontes, dos questionamentos que subsidiam a investigação, e do reconhecimento da impossibilidade de capturar a singularidade de uma vida.

\section{AS FONTES DOCUMENTAIS E O EMERGIR DE SUBJETIVIDADES}

Se muitas são as questões enredadas na vida, outras tantas são as que dizem respeito ao trabalho com fontes documentais. Desde os problemas teórico-metodológicos, de acesso aos acervos, considerações sobre os aspectos de produção, circulação e o entendimento das razões para sua localização em determinados espaços. Cada documento forma-se de um circuito de significados que fundamentaram sua elaboração. De maneira intencional, os discursos são materializados, sendo impossível destituí-los de suas ligações com valores que se inscrevem nos ideários e representações do tempo passado. De acordo com Certeau (2008, p.66):

Toda pesquisa histórica se articula com um lugar de produção sócio-econômico, político e cultural... Ela está, pois, submetida a imposições, ligada a privilégios, enraizada em uma particularidade. É em função deste lugar que se instauram os métodos, que se delineia uma topografia de interesses, que os documentos e as questões, que lhes serão propostas, se organizam.

As representações construídas através da escrita são analisadas junto aos outros aspectos que lhes atribuem significados próprios, sejam estes, marcas de sua temporalidade ou até mesmo os suportes e suas composições físico-químicas, pensadas em função da durabilidade, garantindo legitimidade ao conteúdo veiculado. Características físicas que resultam de processos sociais, desde a concepção do documento, seus usos e formas de preservação expressos nos vestígios encontrados no suporte material.

Os historiadores da educação dependem, nas suas investigações, não apenas das questões formuladas dentro de certas matrizes 


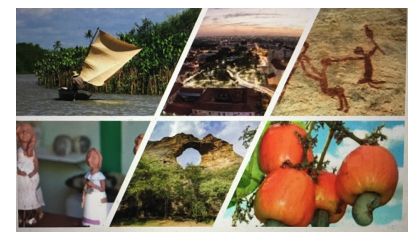

teóricas, mas também dos materiais históricos que podem contar. Não fazemos bons trabalhos na área sem respeitar a empiria contra a qual lutamos; e todos já nos deparamos com a dificuldade de recolher fontes impressas e arquivísticas, geralmente lacunares, parcelares e residuais. Apesar dessas dificuldades, é justamente no manuseio crítico das fontes que o pedagogo ganha distância, tornando-se, pela sua prática e pelo seu projeto, um historiador. (NUNES e CARVALHO, 1999, pp.22-23).

Uma das principais questões que rodeiam os estudos que tenho realizado acerca da vida e atuação de Nestor Lima é o fato de não ter tido acesso a documentos advindos de um arquivo pessoal. Considero que esta é uma lacuna que a partir das leituras críticas busco amenizar. Ao ler os seus relatórios de viagem, penso sobre os meses que se lançou nessas travessias, as possíveis cartas trocadas com familiares, amigos, colegas de trabalho. Os presentes recebidos, alguns que ele mencionou ter guardado com carinho, os telegramas trocados com o governador, transcritos no primeiro relatório e tantos outros materiais que pudessem apontar caminhos de pesquisa e novos significados.

A partir das ausências, busquei alternativas de mapeamento de documentos, para que mesmo por meio de materiais biográficos secundários, pudesse criar alternativas de trabalho com o objeto escolhido. Não há como pensar acerca das ideias dissociadas das práticas dos agentes que as produziram, bem como as formas impressas que as fizeram circular. Assim, intuo que o trabalho com fontes históricas é cercado por problematizações acerca da produção da própria fonte.

A escrita da narrativa abre espaços e oportuniza, às professoras e professores em processo de formação, falar-ouvir e ler-escrever sobre suas experiências formadoras, descortinar possibilidades sobre a formação através do vivido. A construção da narração inscreve-se na subjetividade e estrutura-se num tempo, que não é linear, mas num tempo da consciência de si, das representações que o sujeito constrói de si mesmo. (SOUZA, 2007, p.69). 


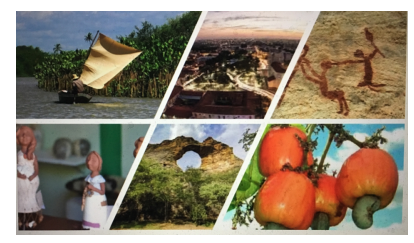

Das fontes também emergiram as ações políticas de Nestor Lima não se resumem às discussões partidárias ou apontamentos às formas de governar em determinados estados ou países. Percebo em sua atuação ações políticas, que o situam em um lugar de prestígio social. Durante diversos momentos de sua escrita, faz referência às experiências vividas, rememora situações e remete-se à momentos de destaque que vivenciou no cumprimento de suas atividades profissionais. Para tanto, nas leituras de suas narrativas, é importante atentar que:

A escrita memorialística desvela a necessidade de testemunhar onde o narrador é o senhor do seu passado, autoridade, condutor da trama, recuperando mediante o seu relato, a própria memória. Jogo de ficção e história e cheio de armadilhas.[...] $\mathrm{O}$ ato de lembrar não significa necessariamente reviver algo tal como foi, disse Ecléa Bose. Implica sempre em reconstrução, reinvenção esta que não dispensa as representações da consciência atual. $\mathrm{O}$ fato lembrado é sempre atualizado pelas mudanças do próprio indivíduo, as transformações de seus juízos e valores sobre a realidade. $O$ passado lembrado tem a marca da contemporaneidade e, isso rompe com a ilusão de identidade entre lembrança e fato. (MIGNOT, 2002, p.46-47).

Um momento específico de suas recordações me prende a atenção. Em meio às discussões sobre princípios, métodos, procedimentos, instalações das instituições visitadas e docência, dedicou muitas linhas do texto para descrever uma situação atípica vivida durante o trânsito comissionado. Com riqueza de detalhes, descreveu sobre sua participação em uma aula:

[...] Dirigimo-nos à classe do primeiro ano onde uma normalista praticante dava uma lição de leitura sobre o ninho (el nido). $\mathrm{O}$ método era o da palavração. Assistiam-na turmas do $4^{\circ}$ ano normal. Conhecimento do som $h i$, combinação do som em $f-i, p$ $i, t-i, j-i$. Uso do quadro negro. Exercício de palavras de sons análogos; variação de exemplos. A classe éra atenta, embora a praticante também possuísse nervos... As perguntas eram bem dirigidas e prontamente respondidas pela numerosa classe de crianças de 6 e 7 anos (chiquitos). Terminada a classe, passámo- 


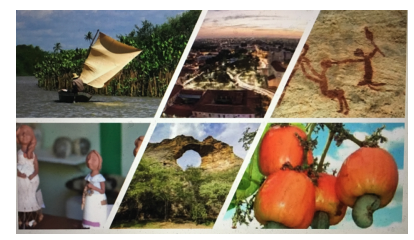

nos todas as normalistas, a Diretora, o Inspetor Geral e eu, ao salão de crítica pedagógica. Foi ouvida logo pela Diretora a praticante que fizera a lição. Inquerida sobre estava contente com o que fizera, assegurou que ficara satisfeita, embora notasse que, em vez da "palavra" nido, tivesse dito o som. As outras colegas, uma a uma, a convite da Diretora, interviram na crítica e apontaram sérios defeitos ou simples enganos da lição. A praticante explicava e defendia-se. A diretora falou para julgar o trabalho, apontou os erros e mostrou como deveriam ser corrigidos, aceitando uns pontos da crítica e desprezando outros. Ela dissertou sobre Pedagogia e Psicologia infantil, interessando nisso todas as alunas. Fui, afinal, convidado para falar àquela classe: - acedi e falei em vernáculo brasileiro, a pedido insistente das ouvintes. Comecei recordando que àquela hora, eram quatro da tarde em Natal, estaria eu em face das minhas alunas do $4^{\circ}$ ano a dizer-lhes o que me convidavam a dizer ali: a opinião acerca de métodos de leitura inicial. Estabeleci os princípios, discuti a tese e demonstrei, segundo a minha prática pessoal, as excelências do método analítico de sentenciação. Depois de mais de vinte minutos de exposição, dei por finda a coparticipação na critica. Recebi gentis parabéns e agradecimentos, enquanto que a diretora pedia-me que voltasse para continuar na troca de ideias e pontos de vista profissionais. (LIMA, 1923, pp.16-17).

Uma das possibilidades na análise sócio-histórica da profissão docente é estudar como os indivíduos configuram suas experiências na criação de uma consciência de si, a partir dos caminhos que percorrem, considerando como se percebem ou auto-representam em meio às ações profissionais. Nóvoa e Finguer (1988, p.116) sinalizam que "a formação é inevitavelmente um trabalho de reflexão sobre os percursos de vida", o que compreendo a luz das ideias de Ferrarotti (1998) quando afirma que a biografia se torna instrumento sociológico que parece poder vir a assegurar esta mediação do ato à estrutura, de uma história individual à história social.

Em sua narrativa, Nestor dos Santos Lima referiu-se aos seus sentimentos frente às diversas manifestações de homenagens que presenciou, fossem estas de aclamações à pátria brasileira, ou saudações e boas vindas pela sua visita nos espaços educacionais. Sobre sua passagem pela "Escuela Normal para Niñas", destacou: 


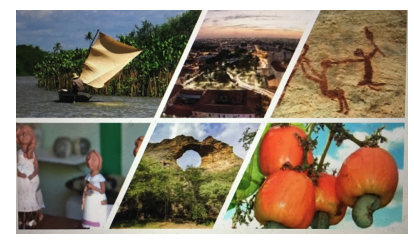

Fez-se um interessante momento escolar em honra do Brasil. As alunas que a 07 de setembro de 1922, haviam tomado parte nas festas brasileiras da Independência, vieram recitar junto a mim, em puro castelhano, sonetos de Bilac, Corrêa e outros, e em português, bem pronunciado, uma linda saudação ao Brasil. Agradeci-lhes essa tocante cortesia e amabilidade. (LIMA, 1923, p.17).

Por diversas vezes recordou as situações de enaltecimento seja por sua nacionalidade, com referências diretas ao Brasil e sua história. As leituras dessas narrativas são permeadas pelos cuidados com as possibilidades de intervenção do seu autor, como assinala Viñao (1997), sobre a memória não ser exatamente um espelho, mas sim um filtro e que através dele é possível recriação de uma realidade, reinterpretada ao ponto de substituir o que de fato aconteceu. Nesse sentido, analiso suas rememorações a partir dos sentidos de sua presença em um relatório oficial, refletindo acerca do por que e para quem elas destinam.

Topei no corredor de entrada, com todos os cursos formados, cantando mui corretamente o Hino da Proclamação da República Brasileira. A aluna Maria F. Colombo, em nome de todos os alunos da escola "General San Martin" leu, então, a seguinte mensagem de saudações às alunas das escolas primárias "Nosostras, las ninãs argentinas, puras e inocentes, dirigimos a nustras Hermanas, las ninãs del Brasil, um fraternal saludo, deseando que el sepa interpretar nuestro gran desco: que las dós naciones sul-americanas setén sempre ligadas por unn irrompible lazo cuja ideia sea paz, cariño y justicia. Por las alunas de la Esculea General San Martin", Maria F. Colombo. Agradeci comovido, saudando à Argenina e aos seus educadores e alunos. Guardei com carinho a mensagem escrita que ali me foi presente. (LIMA, 1923, p.38).

Ao narrar suas vivências, desnuda os aspectos mais subjetivos não apenas de modo positivo, mas também concedendo espaço para a desaprovação de atitudes de alguns profissionais, como relatou na visita à Escola Profissional Paulo de Frontin, na companhia do inspetor de ensino dr. Caldas Britto que "depois de passar pelas oficinas 


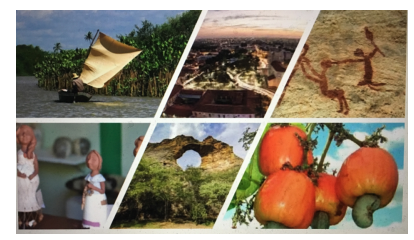

de flores $[\ldots]$ encerramos a visita no momento em que chegava a diretora, que vinha da Exposição e recambiava objetos que haviam estado expostos. Não nos cumprimentou sequer e, menos, indagou do nosso objetivo ali...” (LIMA, 1923, pp.106-107).

\section{ESTRATÉGIAS DE LEGITIMAÇÃO INTELECTUAL NO EXERCÍCIO DA ESCRITA ADMINISTRATIVA}

As menções de agradecimento e expressões das relações políticas se fazem presentes em todos os relatórios escritos por Nestor Lima, seja nos documentos oficiais que versam sobre o funcionamento da Escola Normal, do Departamento de Educação ou mesmo nos das duas viagens comissionadas. Ele faz, frequentemente, associações entre os rumos tomados pela educação e às ações governamentais dos líderes republicanos, que considera e as menciona enquanto administrações inesperadamente pedagógicas.

Em 1912, na escrita do Relatório de Funcionamento da Escola Normal de Natal, Nestor Lima sugeriu a ida de um educador a outras localidades com a finalidade de observar as experiências educacionais desenvolvidas Brasil afora, com o intuito de contribuir para as reflexões e encaminhamentos dos trabalhos desempenhados no Rio Grande do Norte. No ano seguinte, estando de férias na então Capital Federal, Rio de Janeiro, recebeu um telegrama do governador Alberto Maranhão, designando-o enquanto funcionário comissionado para cumprir a missão de visitar os espaços educacionais nos centros pedagógicos mais avançados, São Paulo e Rio de Janeiro.

Cabe-me, antes de tudo, louvar a V. Exa. o patriótico empenho constantemente demonstrado pelo progresso do nosso ensino primário e normal, em boa hora reformados pelo decreto $\mathrm{n}^{\circ} 178 \mathrm{de}$ 29 de abril de 1908, empenho que mais uma vez se comprovou com o aplauso e cumprimento dados por V. Exa. à ideia que avantei nas considerações gerais do Relatório da Escola Normal de setembro do ano passado, qual era mandar-se, em comissão e uma vez por outra, aos centros de maior cultura pedagógica do país ou do estrangeiro, profissionais do nosso ensino que, conhecedores das necessidades e condições do meio a serviço de 


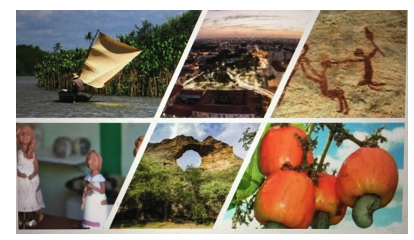

seu cargo, pudessem aí adquirir subsídios para o aperfeiçoamento contínuo da nossa tecnologia didática. (LIMA, 1913, p.3-4).

Apesar de estar na condição de funcionário comissionado do governo, e isso ser algo que a princípio não apontar para algo com muita relevância, percebo que o educador não só destacou como foi escolhido para algumas missões, como também transcreveu os telegramas recebidos, tornando-os públicos. Os relatórios eram direcionados ao Governador, e passavam pelo crivo dos Diretores Gerais da Instrução Pública, logo estes trâmites já eram de conhecimento de ambos. Entendo esses detalhes que permeiam os documentos oficiais escritos por Nestor Lima como estratégia de legitimação intelectual e profissional.

Achando-me na Capital Federal, em gozo de férias, recebi de V. Exa. o seguinte despacho telegráfico:

Natal, 29 de Janeiro de 1913. Ato Governo 28 dezembro fostes comissionado observar melhoramentos técnicos ensino primário normal no e São Paulo aplicáveis estabelecimentos Estado. (assinado) Alberto Maranhão.

Ciente desse ato e aceitando a deferência honrosa, passei para a Capital os despachos seguintes:

Rio, 3 de fevereiro de 1913. Exmo. Governador. Natal. Ciente telegrama Vossa Excelência aceito agradeço confiança.

Rio, 3 de fevereiro de 1913. Diretor Geral Instrução Pública. Natal. Comunico estar exercício comissão Governo Estado. (LIMA, 1913, p.04).

A leitura que realizo dos relatórios oficiais é orientada pelas indagações acerca da construção de sentidos para as ações ali evidenciadas, dos laços estabelecidos e todos os possíveis elementos que dizem respeito à produção daqueles materiais: por que, para quem, com quais motivos e objetivos. Gomez (2016, p.46) afirma que "[...] Los textos adquieren su pleno sentido en el momento en que son leídos, esto es, cuando el lector se apropia de ellos y les dota de una determinada significación. A la postre, tan variada y plural como puede serlo la información, el carácter y la condición de cada lector.” 


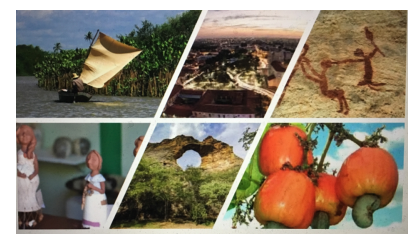

Ainda sobre os deslocamentos e seus significados, dez anos depois, em 1923, Nestor Lima solicitou afastamento da direção da Escola Normal de Natal e se lançou em mais uma viagem, desta vez para além dos limites territoriais nacionais, da qual se constituiu a escrita do segundo relatório de viagem, sob o título "Da organização do ensino normal, profissional e primário no sul do Brasil e no Rio da Prata”. No relatório produzido após a travessia, dedicou a primeira e metade da segunda página aos louvores à administração, na pessoa do governador Antônio José de Melo e Sousa. Percebo que enalteceu a atuação do governador, os rumos que havia tomado a educação do estado, agradecendo, ainda, por seu nome ter sido escolhido para este posto.

Avalio que essas experiências colaboraram para a construção de sua identidade profissional, o conduzindo à ocupação de outros cargos e espaços. Os elementos formativos que convergem para as transformações ocorridas em sua vida de educador, de certo modo, expressaram-se, também, nas mudanças e educacionais das primeiras décadas do século XX no Rio Grande do Norte, sobretudo a partir de sua gestão no Departamento de Educação do Estado. No Relatório Manuscrito do Departamento de Educação (1924), iniciou o texto com os agradecimentos e louvores à atuação política do então governador José Augusto Bezerra de Medeiros:

[...] A gratidão de todo pessoal que compõe o Departamento de Educação, pelos grandes benefícios que do fecundo e generoso governo vigente tão [ilegível] em relação ao ensino e aos seus servidores. Está vista a confirmação das justas esperanças com que todos conhecemos a indicação do nome de V. Exa. para ocupar o supremo posto da direção do estado e a consagração dos merecimentos do intrépido paladino da instrução que é V. Exa. e se afirma na sua brilhante trajetória no Congresso da República durante nove anos de intenso labor por tão grande causa. (RIO GRANDE DO NORTE, 1924, p.01).

Sua afinidade intelectual com José Augusto Bezerra de Medeiros é amplamente divulgada a partir das parcerias expressas nas páginas do jornal "A República" e até mesmo quando menciona a intermediação do colega na realização das atividades para as 


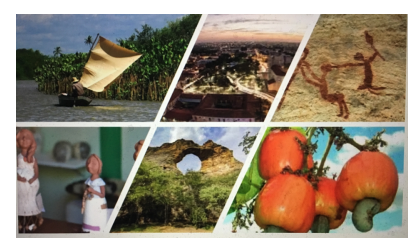

quais Nestor Lima foi designado. "[...] Nosso eminente representante, dr. José Augusto me recomendara por telegrama a vários amigos seus, que ali são autoridades escolares." (LIMA, 1923, p.55). No ano seguinte, a parceria se consolida na administração pública do estado, quando Nestor é indicado para assumir a direção do Departamento de Educação do Rio Grande do Norte.

No acervo do Instituto Histórico e Geográfico do Rio Grande do Norte, diversas fotografias registram as festividades ocorridas pelos mais distintos pontos do estado, no ano de 1927, data que marca o centenário da lei de 15 de outubro de 1827 , que mandou criar escolas de primeiras letras em todas as vilas, cidades e áreas mais populosas do Brasil. Nesse mesmo ano, Nestor Lima dedicou "com admiração e reconhecimento" a José Augusto o livro de sua autoria, sob o título "Um século de ensino primário", tratando da história da instrução pública primária no Rio Grande do Norte a partir da promulgação da referida lei. 

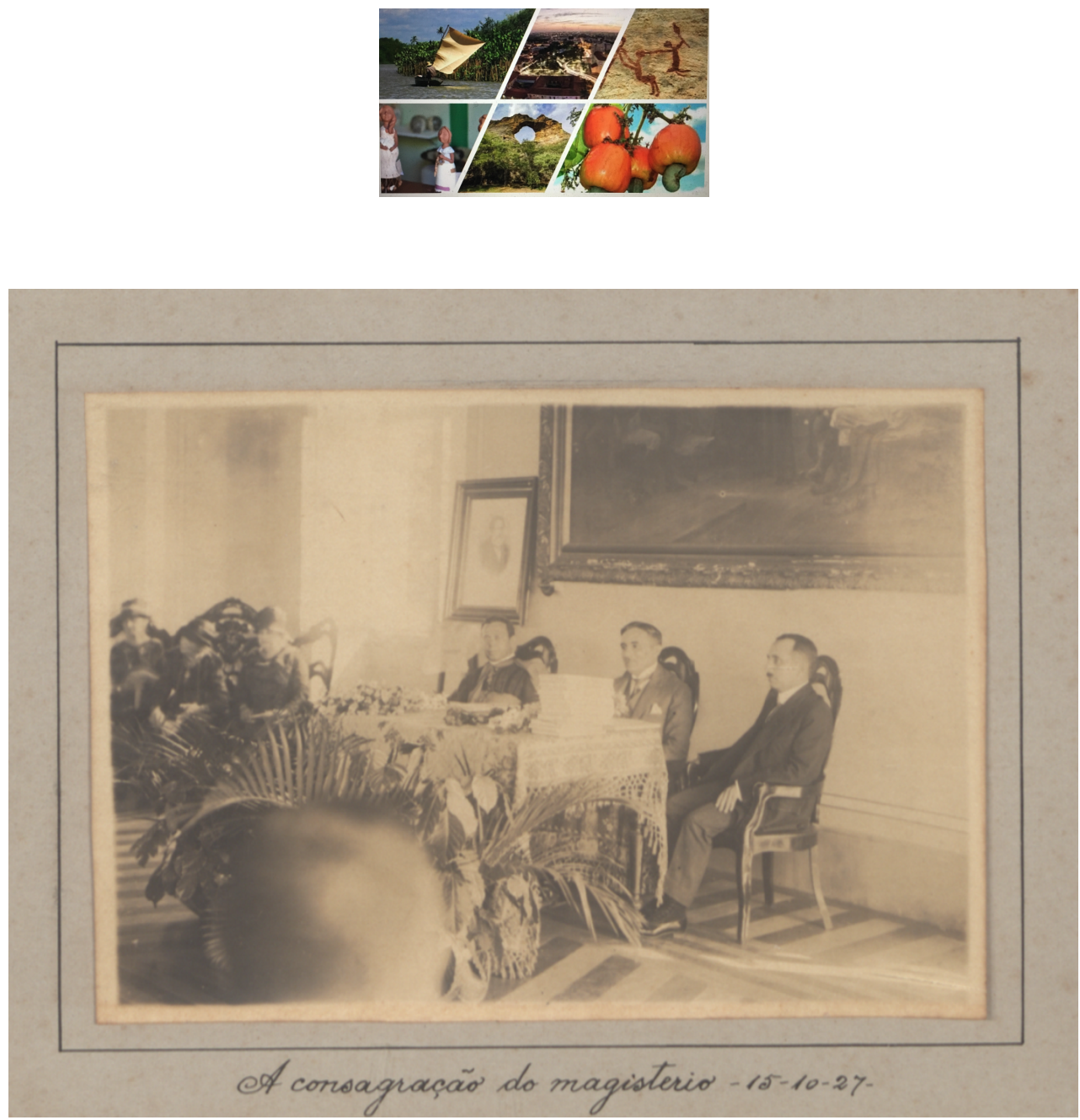

Nestor Lima e José Augusto em comemoração ao centenário da Lei de 15 de outubro de 1927

Acervo: Instituto Histórico e Geográfico do Rio Grande do Norte

Dentre as fotografias sob a guarda do IHGRN, pondero o elevado número de imagens de Grupos Escolares e festividades educacionais em lugares públicos, em sua maioria datadas do ano de 1927, com a presença de Nestor Lima, José Augusto, autoridades religiosas, dentre outros sujeitos que estavam à frente dos processos educacionais no estado. Sobre este aspecto, dialogo com Nunes e Carvalho (1993, p. 23) quando afirmam que "a reflexão sobre as fontes é ao mesmo tempo uma reflexão sobre os limites não só das práticas institucionais, no que diz respeito à localização, conservação e divulgação de acervos, mas também das práticas discursivas, no âmbito da história.”. Através dessas fontes são evidenciadas ações políticas e educativas, constitutivas de representações sociais daqueles que promoveram tais iniciativas. 


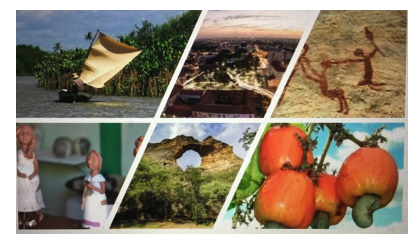

Sobre os assuntos políticos presentes no relatório, ressalto que não apenas fazem menção aos assuntos restritos aos territórios norte-rio-grandenses. Nestor Lima teceu ácidas críticas às questões políticas dos demais estados, como a exemplo, da situação em que se encontrava o Rio de Janeiro:

A esplendida metrópole Brasileira, que serve de padrão de orgulho ao nosso sentimento nacional, tem realizado alguma coisa no aspecto educativo: mas é ainda bem pouco o seu resultado, que não está na relatividade dos progressos e vantagens que ali se goza, sob outros aspectos de sua cidade civilizada e moderna. À frente dos destinos da instrução carioca está o espírito cintilante do dr. A. Carneiro Leão, meu antigo condiscípulo na Escola de Direito do Recife, meu e conhecido publicista de assuntos pedagógicos. Sua atuação deverá ser proveitosa; mas, talvez, tenha de arear com a maré montante de causas regionais e locais que tanto desvirtuam as boas intenções: a politicagem, um Conselho Municipal essencialmente politiqueiro, a proteção aos afilhados, a imprensa mal orientada, as frequentes reformas e contrarreformas, a exiguidade dos recursos municipais para o ensino, todo um mundo de preconceitos e arcaísmos não permitirão que melhore tão cedo a triste situação. (LIMA, 1923, p. 101).

Nas suas impressões gerais sobre a educação, afirmou perceber nas instituições visitadas um grande interesse por parte dos profissionais do ensino, porém, nos mais diversos lugares ressoava uma mesma alegação de escassez de recursos para o combate ao analfabetismo. Sobre esse aspecto, recriminou com veemência tais discursos quando expõe que "é a eterna carência de dinheiro, que se não regatearia para couraçados e armamentos, mas é sempre tão minguado para o ensino [...] o que em geral nos move e apavora é o excesso de despesas públicas que tais serviços acarretam!... Poucos, porém, muito poucos se assombram com o número de analfabetos...” (LIMA, 1923, pp. 119-120).

Em sua visita à escola Epitácio Pessoa expressa tristeza, descrença e inclusive descreve uma situação em que murmurou para um amigo que o acompanhava nas visitas, o seu descontentamento com a situação na instituição: 


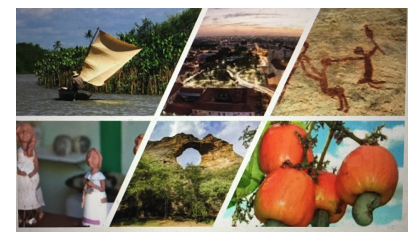

Percorri o prédio novo e inaugurado por ocasião do Centenário. Consta de dois andares, sob a face de duas ruas batidas de sol em cheio: salas grandes e saletas de espera acomodam as classes, sendo algumas quase triangulares de não mais de 3 por 4 metros. Ao examinar tudo aquilo, que se fez na Capital Federal, por cerca de 500 contos e para celebrar o feito maior da nossa História, senti uma expressão de revolta e de acabrunhamento. Isto é um crime de lesa civilização... Murmurei ao meu amigo. E é mesmo, porém, da natureza daqueles que não se punem, porque sua vítima é anônima e futura. Saí dali, riste e descrente de uma correção para os erros do ensino na mais bela capital do mundo: o Rio de Janeiro. (LIMA, 1923, p.104-105).

Ao mesmo tempo, que teceu suas críticas, ofereceu respaldo para elas ao rememorar afirmações proferidas pelo governador Antonio de Melo e Sousa, com quem comungava das posições políticas. "Bem haja o governo de V.Exa. de quem, certa vez, ouvi deslumbrado: 'com instrução, não me importa embocar os cofres do Estado'! Tivessem todos os homens públicos uma visão igual à de $\mathrm{V}$. Exa. e já bem longe iríamos neste campo de atividade". (LIMA, 1923, p.120)

Apresentou os alarmantes dados que mostram o Brasil ocupando o último lugar pela percentagem de analfabetos em relação aos demais países do cenário mundial. Segundo suas palavras, tremiam a pena e a consciência ao reconhecer que muito ainda, ou tudo, havia de se fazer no combate ao grande mal do analfabetismo, que prejudicava $85 \%$ do povo brasileiro. "O confronto destas cifras de percentagens aterradoras deveria calar no ânimo de todos os brasileiros, para despertar a alma nacional e empreender a cruzada santa do combate sem tréguas à ignorância volumosa que nos empobrece e humilha perante as outras nações do Universo civilizado.” (LIMA, 1923, p.122).

Faço uso das diversas falas de Nestor Lima com enfoque nas questões políticas, de investimento e educação por entender que o conhecimento da realidade educacional nacional e de certo modo, internacional - pela bagagem de conhecimentos que possuía ou pelos caminhos por onde andou - converteu-se em um somatório de experiências que foram transformadoras para a vida do educador, inclusive talvez o legitimando para Revista Caminhos da Educação: diálogos, culturas e diversidades. CAEDU/UFPI 


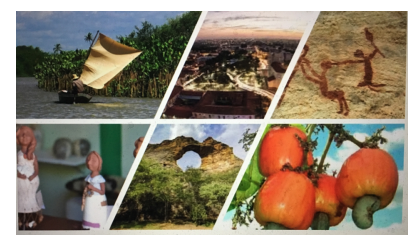

condição de sujeito conhecedor das necessidades e possibilidades das mudanças necessárias à educação no estado. Conjecturo isso por perceber que depois da ocupação de cargos na educação e produção de relatórios dos trabalhos desenvolvidos, Nestor Lima é convidado a dirigir a Instrução Pública no estado, em 1924, no governo de José Augusto Bezerra de Medeiros.

Essa indicação significou transformações não só relacionadas à trajetória de vida profissional do educador, como da própria educação no Rio Grande do Norte. De posse do cargo, instituiu muitas das coisas que havia apontado em seus afazeres anteriores. Criou o Departamento de Educação do Estado e Conselho de Educação, reorganizando completamente o ensino, escreveu regimentos internos para Grupos Escolares, Escolas Isoladas, Escolas Rudimentares e retoma a atividade de inspeção do ensino, que estava quase crítica desde o período imperial.

\section{CONSIDERAÇÕES}

Nos relatórios de viagem, ou mesmo textos publicados em jornais e revistas, Nestor Lima se fez também escritor de sua história, desnudando seu olhar para temas da sociedade vigente, ao mesmo tempo em que emitia suas opiniões e se auto-representava como protagonista nos cenários de discussões políticas e educacionais. Evidencio como os seus escritos permitiram-me construir representações para além das presentes apenas em seu percurso de formação profissional. A partir do relevo intencional aos aspectos do cotidiano, às relações e iniciativas tomadas, reflito que registrava sobre si o que de fato desejou que emergisse; cogito o que para a posteridade desejou conceber.

Mesmo escrevendo um documento com finalidades administrativas, em momento algum se furtou de exibir com detalhes seus anseios profissionais particulares, desde a sua decisão de ampliar a viagem para os países estrangeiros Argentina e Uruguai, conforme escreveu: 


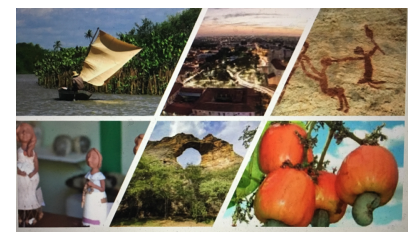

Um dos mais antigos anseios de minha carreira no ensino era conhecer de perto o adiantado centro de cultura, que é a capital da República Argentina. Acostumado a admirar os seus progressos nos diversos aspectos da civilização aprimorada, desejava, desde muito, pôr-me em contato com aquele povo irmão e com seus institutos pedagógicos. (LIMA, 1923, p.34).

Justificou com clareza que algumas de suas visitas foram suscitadas por aspirações pessoais e no interior do relatório de sua segunda viagem comissionada organiza os registros por regiões e instituições educacionais e/ou educativas visitadas, mas, além disso, dedicou um tópico unicamente para descrever suas observações pessoais, intitulando-o "Visita a outras instituições". Neste espaço escreveu: "segundo um antigo desejo, visitei três grandes estabelecimentos da capital de São Paulo, dignos de seu progresso e capazes de honrarem qualquer grande cidade do mundo: o Museu Paulista, o Butantã e a Penitenciária.” (LIMA, 1923, p.71).

Nesse mesmo sentido referiu-se, por exemplo, às obras do Monumento do Centenário, afirmando que todos os adjetivos mencionados não seriam capazes de descrever a emoção daquela visita. "Tenho a impressão que cada brasileiro deveria ir até ali admirar naquele esforço de arte e decoração, o nosso passado histórico e reverenciar, como numa Catedral da Pátria, os grandes heróis da nossa libertação. Devera ser ali o lugar sagrado das nossas romarias cívicas: o altar da Pátria Brasileira." (LIMA, 1923, p.72).

Confesso ter sido difícil a ação de selecionar, dentre os tantos trechos que o percebo emergir, aqueles que retratam sua vida de algum modo através das experiências que possivelmente o transformaram pessoal e profissionalmente. Impossível não se sentir tal qual o viajante quando fala de sua satisfação ao visitar Ouro Preto e pisar em um lugar tão emblemático da história do nosso país. "A 17 de Junho, deixei Belo Horizonte, para visitar a lendária cidade de Ouro Preto, antiga capital do Estado e da Província. As razões dessa visita eram o encanto e o interesse pelas tradições da famosa Vila Rica dos 


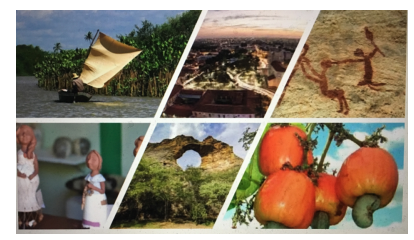

Inconfidentes, das quais me saturei durante os dois dias que lá permaneci.”(LIMA, 1923, p.90).

Petrucci (1999, p.290) garante que, "para quem estuda criticamente os produtos das culturas escritas do passado, não pode haver questão mais fascinante do que aquela que se faz a propósito do por que e do como se foram formando e duraram no tempo os testemunhos escritos das sociedades históricas". Por quantas seleções pode ter passado o conteúdo do documento? Quais outras situações podem ter sido camufladas em detrimento às que mereceram destaque?

Refletir acerca dos muitos propósitos existentes no documento e para além dele, foi imprescindível para as construções de sentidos possíveis a partir dos discursos veiculados e ações sistematizadas por entre as linhas do material. Ao mesmo tempo em que percebo essa variedade de elementos que envolvem os registros, reconheço que tive contato apenas com uma versão, com a visão particular do autor.

Diante disso percebo os relatórios, sejam os das viagens comissionadas, de funcionamento da Escola Normal, ou do Departamento de Educação enquanto instrumentos falsamente neutros. Se a princípio eles se caracterizam como suportes destinados apenas a tratar de pragmáticas questões institucionais, seu autor os transforma em espaços de fala, tecendo críticas e/ou exaltação aos modos de funcionamento da educação por onde o seu olhar fio capaz de alcançar. Esses instrumentos permitiram o registro de desejos, emoções, aspirações; da vida que não se prende ou limita às linhas de documentos escritos e se manifesta de muitas formas nas narrativas de um educador.

\section{REFERÊNCIAS:}

ALMADA, M. Cultura escrita e materialidade: possibilidades interdisciplinares de pesquisa. Pós: Belo Horizonte, v. 4, n. 8, p. 134 - 147, nov. 2014.

AMORIM, S. R. M. Viagem como missão: intercâmbio pedagógico do educador Nestor dos Santos Lima (1913-1923). Tese (Doutorado em Educação), Universidade do Estado do Rio de Janeiro, 2017.

BACELLAR C. Fontes documentais. Uso e mau uso dos arquivos. In: PINSKY C.B., Fontes históricas, 2 ed. São Paulo: Contexto, 2010.

BRASIL. Actos de Poder. Lei de 15 de outubro de 1827. 


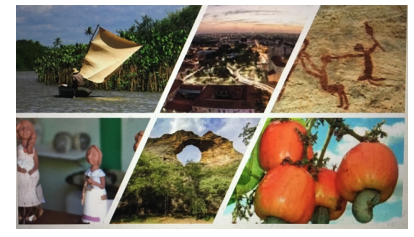

CASTILLO GÓMEZ, A. "La Corte de Cadmo: apuntes para una historia social de la cultura escrita". Revista de Historiografía, Madrid, n. 1, pp. 89-98, 2004.

Leer y oir leer. Ensaios sobre la lectura en los Siglos de Oro. Madrid: Iberoamericana - Vervuert, 2016.

CERTEAU, M. A escrita da História. Tradução de Maria de Lourdes Menezes; revisão de Arno Vogel. 2 ed. Rio de Janeiro: Forense Universitária, 2008.

LIMA, N. S. Melhoramentos técnicos do ensino primário e normal. Natal: Typ. Do Instituto, 1913.

. Da organização do ensino normal, profissional e primário no sul do Brasil e no Rio da Prata. Natal: Typ. d'A República, 1923.

CARVALHO, M. M. C. Reformas da instrução pública. In: LOPES, Eliane Marta Teixeira; FARIA FILHO, Luciano Mendes; VEIGA, Cynthia Greive. (Org.). 500 anos de educação no Brasil. Belo Horizonte: Autêntica, 2003.

FERRAROTTI, F. Sobre a autonomia do método biográfico. In: NÓVOA, A.; FINGER, M. (Org.). O método (auto)biográfico e a formação. Lisboa: Departamento de Recursos Humanos/ Ministério da Saúde. 1988. p. 17-34.

MARTINS, H. Lista Geral dos Bacharéis que tem obtido o respectivo grau na Faculdade de Direito do Recife, desde a sua fundação em Olinda, no ano de 1828 até o ano de 1931. Recife: Tipografia Diário da Manhã, 2ªed. 1931.

MIGNOT, A. C. V. Baú de Memórias, bastidores de histórias: o legado pioneiro de Armanda Álvaro Alberto. Bragança Paulista: EDUSF, 2002.

; SOUZA, E. C. Modos de viver, narrar e guardar: diálogos cruzados sobre pesquisa (auto)biográfica. Revista Linhas. Florianópolis, v. 16, n. 32, p. 10 - 33, set./dez. 2015.

NÓVOA, A.; FINGER, M. O método (auto)biográfico e a formação. Lisboa: MS/DRHS/CFAP, 1988.

NUNES, C.; CARVALHO, M. M. C. de. Historiografia da Educação e Fontes. In: CADERNOS ANPED, n5. Caxambu: ANPED, setembro, 1993.

PETRUCCI, A. Alfabetismo, escritura, sociedad. Barcelona: Gedisa Editorial, 1999.In: ALMADA, M. Cultura escrita e materialidade: possibilidades interdisciplinares de pesquisa. Pós: Belo Horizonte, v. 4, n. 8, p. 134 - 147, nov. 2014.

RIO GRANDE DO NORTE. Relatório da Escola Normal de Natal apresentado ao Dr. Manoel Dantas, Diretor de Instrução Pública. Natal, 1912, 38 p. (manuscrito).

Relatório do Departamento de Educação. Natal, 1924, 45p. (manuscrito)

SOUZA, E. C. (Auto)biografia, histórias de vida e práticas de formação. In: NASCIMENTO, AD., and HETKOWSKI, TM., Orgs. Memória e formação de professores [online]. Salvador: EDUFBA, 2007.

; MENEZES, J. M. F. História da Educação na Bahia: recortes e aproximações sobre a constituição do campo. In: VASCONCELOS, J. G; NASCIMENTO, J. C. (Org.). História da Educação no Nordeste Brasileiro. Fortaleza: UFC Edições, 2006, p. 136-153. 


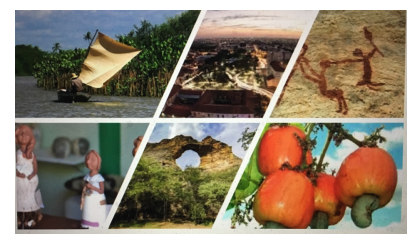

VASCONCELOS, M. C. C. Pesquisa em História da Educação: Acervos, arquivos e a utilização de fontes. FRONTEIRAS: Journal of Social, Technological and Environmental Science, Anápolis-Goiás, v.3, n.3, jul.-dez. 2014, p.33-47.

VIÑAO, A. Las autobiografías, memorias y diarios como fuente histórico-educativa: tipologia y usos. TEIAS: Revista da Faculdade de Educação/UERJ. n.1, jun. 2000, p.8297. 